\title{
Epidemiology, Clinical Characteristics, and Outcomes of a Large Cohort of COVID-19 Outpatients in Michigan
}

\author{
Alexandra Halalau $\mathbb{1}^{1,2}$ \\ Fadi Odish ${ }^{3}$ \\ Zaid Imam ${ }^{4}$ \\ Aryana Sharrak ${ }^{2}$ \\ Evan Brickner ${ }^{2}$ \\ Paul Bumki Lee $\mathbb{D}^{2}$ \\ Adam Foglesong' \\ Adrian Michel' \\ Inayat Gill (D) \\ Lihua $\mathrm{Qu}^{2,5}$ \\ Amr E Abbas ${ }^{2,6}$ \\ Christopher F Carpenter ${ }^{1,2,7}$
}

'Internal Medicine Department, Beaumont Health, Royal Oak, MI, USA; ${ }^{2}$ Oakland University William Beaumont School of Medicine, Rochester, MI, USA;

${ }^{3}$ Section of Gastroenterology and Hepatology, Department of Interna Medicine, Wright State University, Dayton, OH, USA; ${ }^{4}$ Division of Gastroenterology and Hepatology, Department of Internal Medicine, Beaumont Health, Royal Oak, MI, USA; ${ }^{5}$ Outcome Research Department, Research Institute Beaumont Health, Royal Oak, MI, USA; ${ }^{6}$ Cardiovascular Department, Beaumont Health, Royal Oak, MI, USA; ${ }^{7}$ Infectious Disease Section, Beaumont Health, Royal Oak, MI, USA
Correspondence: Alexandra Halalau William Beaumont Hospital, 360I W 13 Mile Road, Royal Oak, MI, 48073, USA $\mathrm{Tel}+$ I 248 55I-348I

Email Alexandra.Halalau@beaumont.org
Background: Most outpatients with coronavirus disease 2019 (COVID-19) do not initially demonstrate severe features requiring hospitalization. Understanding this population's epidemiological and clinical characteristics to allow outcome anticipation is crucial in healthcare resource allocation.

Methods: Retrospective, multicenter ( 8 hospitals) study reporting on 821 patients diagnosed with COVID-19 by real-time reverse transcriptase-polymerase chain reaction assay of nasopharyngeal swabs and discharged home to self-isolate after evaluation in emergency departments (EDs) within Beaumont Health System in March, 2020. Outcomes were collected through April 14, 2020, with a minimum of 12 day follow-up and included subsequent ED visit, admission status, and mortality.

Results: Of the 821 patients, mean age was 49.3 years (SD 15.7), $46.8 \%$ were male and $55.1 \%$ were African-American. Cough was the most frequent symptom in $78.2 \%$ of patients with a median duration of 3 days (IQR 2-7), and other symptoms included fever $62.1 \%$, rhinorrhea or nasal congestion $35.1 \%$ and dyspnea $31.2 \%$. ACEI/ARBs usage was reported in $28.7 \%$ patients and $34.0 \%$ had diabetes mellitus. Return to the ED for re-evaluation was reported in $19.2 \%$ of patients from whom $54.4 \%$ were admitted. The patients eventually admitted to the hospital were older (mean age 54.4 vs 48.7 years, $p=0.002$ ), had higher BMI $\left(35.4 \mathrm{~kg} / \mathrm{m}^{2}\right.$ vs $\left.31.9 \mathrm{~kg} / \mathrm{m}^{2}, p=0.004\right)$, were more likely male ( $58.1 \%$ vs $\left.45.4 \%, p=0.026\right)$, and more likely to have hypertension $(52.3 \%$ vs $29.4 \%, p<0.001)$, diabetes mellitus $(74.4 \%$ vs $29.3 \%, p<0.001)$ or prediabetes $(25.6 \%$ vs $8.4 \%, p<0.001)$, COPD (39.5\% vs $5.4 \%$, $p<0.001$ ), and OSA ( $36 \%$ vs $19 \%, p<0.001)$. The overall mortality rate was $1.3 \%$.

Conclusion: We found that $80.8 \%$ of patients did not return to the ED for re-evaluation. Sending patients with COVID-19 home if they experience mild symptoms is a safe approach for most patients and might mitigate some of the financial and staffing pressures on healthcare systems.

Keywords: COVID-19, infectious disease, epidemiology, SARS-CoV-2, demographics, outpatient

\section{Introduction}

Coronaviruses are single stranded RNA viruses that have been implicated in severe acute respiratory syndrome (SARS) and Middle East respiratory syndrome (MERS) in 2002 and 2012, respectively. ${ }^{1,2}$ On December 31, 2019, the first case of the 2019 novel coronavirus disease (COVID-19) was reported in Wuhan, China. ${ }^{3}$ At the time, it was reported that the virus may have originated from a local seafood market, and may have 
been transmitted from bats to humans. ${ }^{4}$ The virus responsible for this infection was identified as severe acute respiratory syndrome coronavirus 2 (SARS-CoV-2) likely of zoonotic origin. $^{5,6}$ SARS-CoV-2 is transmitted mainly through respiratory droplets, but may also spread via the fecal-oral route and through aerosolization. ${ }^{7,8}$ As of February 2021, $27,885,188$ cases have been confirmed in the United states alone, ${ }^{9}$ with 582,671 cases and 15,404 deaths in Michigan. ${ }^{10}$

Reports of clinical characteristics have varied since the start of the pandemic. In April 2020, a study from Wuhan reported that in a cohort of 7736 patients, $88.7 \%$ developed fever, $67.8 \%$ had a cough, $5 \%$ had nausea or vomiting, and $3.8 \%$ had diarrhea. ${ }^{11}$ A Bulgarian study reporting on 138 hospitalized patients identified fatigue, cough, headache, myalgias, arthralgias, sore throat, chest tightness, and fever as the most common presenting symptoms. ${ }^{12}$ A multicentric study involving 18 European hospitals from March to April 2020, reported clinical symptoms in a decreasing order of incidence as follows: headache, loss of smell, nasal obstruction, cough, asthenia, myalgia, rhinorrhea, gustatory dysfunction, sore throat, and fever. ${ }^{13}$

Testing for SARS-CoV-2 has become increasingly available across the United States, resulting in greater disease detection. The vast majority of patients who test positive will demonstrate a non-lethal course of illness. In order to conserve hospital resources for patients with severe forms of COVID-19, stable patients are sent home, with instructions to self-isolate and monitor their symptoms. The largest cohort of greater than 44,000 confirmed COVID-19 patients in China showed that $81 \%$ displayed "mild" illness severity, defined as cases with no pneumonia or mild pneumonia, but these patients were immediately isolated within designated wards in existing hospitals, and received hospital care during their illness. No deaths were reported among mild or severe cases while the case-fatality rate was $49 \%$ among "critical" cases (respiratory failure, septic shock, and/or multiple organ dysfunction or failure). ${ }^{14}$ Based on current data, only $19 \%$ of patients with known COVID-19 in the United States are hospitalized with $6 \%$ admitted to the intensive care unit. ${ }^{15}$

Outpatient management of COVID-19 has been rapidly evolving throughout the pandemic. Most care for mild disease is supportive. While studies have found that systemic corticosteroids can reduce mortality in hospitalized patients, no benefit was found in the outpatient management. In addition, remdesivir has been shown to reduce recovery time in hospitalized patients, but there is not sufficient data for its use in the outpatient setting. ${ }^{16}$ In January 2021, McCullough et al discussed early outpatient treatment of
COVID-19. They discussed the use of zinc lozenges, antivirals and antibiotics, corticosteroids, and antiplatelet/antithrombotic therapy. ${ }^{17}$ Further research needs to be done on optimizing outpatient treatment of COVID-19.

The data on symptom variability and outcomes for patients who are found to have COVID-19 and sent home to self-isolate is limited. We describe the demographics, initial clinical presentation, and outcomes of a large cohort of outpatients with COVID-19.

\section{Design and Methods Study Design and Setting}

This multicenter observational retrospective cohort study was conducted at Beaumont Health, the largest healthcare system in Michigan, which includes 8 hospitals in Southeast Michigan, providing care for approximately one third of patients in the Detroit Metropolitan area.

\section{Ethics Statement}

Prior to data collection, the study was given exempt approval per the Beaumont Institutional Review Board (approval number RB2020-105, approved April 1, 2020).

\section{Patients}

Patients were included in the study if they tested positive for SARS-CoV-2 at any date up to April 1, 2020, after evaluation at any of the EDs across the eight hospitals, and subsequently discharged home. All patients with a negative test for SARS-CoV-2 were excluded from the study. Per the WHO guidance, laboratory confirmation for COVID-19 was defined as a positive result of real-time reverse transcriptase-polymerase chain reaction (RT-PCR) assay of nasopharyngeal swabs. ${ }^{18}$ Based on Michigan Department of Health requirements over the study period, testing was offered if patients experienced moderate cough or fever over $100.4^{\circ} \mathrm{F}$, and if they had chronic kidney disease, heart disease, diabetes, chronic lung disease, were receiving immunosuppression medication, or were immunocompromised due to cancer treatment, recent surgeries or other conditions, suggesting high risk for severe disease. ${ }^{19}$

\section{Variables and Data Source}

Patient information was reviewed, and the following variables were collected: patient age, race, gender, Body Mass Index (BMI), past medical history, clinical symptoms, and home medications. Majority of the data were abstracted 
through automated reports generated through ToadDataPoint multi-platform database query tool from Beaumont's electronic medical record (EPIC System, Verona, WI, USA). A manual retrospective chart review was performed to confirm that the patients were sent home after being tested and to collect the clinical symptomatology upon initial presentation.

\section{Outcome Data}

Data were reported as follows: when patients had multiple follow-up ED visits, admitted inpatient outcome was considered as any ED visit for the patient that resulted in admission. Time to the ED visit was reported based on visits, not per patient. Manual collection of the admission outcomes was performed for patients transferred to another institution or to hospice to ensure the completeness of the reported data.

\section{Statistical Analysis}

The biostatistics department at Beaumont Health performed statistical analysis of the data. Continuous variables were reported as means and standard deviations (SD) or medians and interquartile ranges (IQR) depending on normality. Categorical variables were reported as frequencies and percentages. Two-sample independent $t$-tests or non-parametric equivalent tests and Pearson Chi-Square Tests were used to evaluate continuous and categorical variables, respectively. $P$-values $<0.05$ demonstrated statistical significance. Univariate and multivariate regression analysis was also reported. Analyses were performed using SAS 9.4, SAS Institute Inc., Cary, NC, USA.

\section{Results}

\section{Demographic Data \& Comorbidities}

(Table 1) From the first day when testing for SARS-CoV-2 became available within our health system until April 1, 2020, 821 patients were evaluated in the ED, tested positive for SARS-CoV-2, and discharged home to self-isolate without a hospital admission. Mean age of patients was 49.3 years (SD 15.7), 46.8\% were male, and $55.1 \%$ were African-American. Mean BMI was $32.4 \mathrm{~kg} / \mathrm{m}^{2}$ (SD 7.7) and $73.4 \%$ were non-smokers. The most common comorbidity in this cohort was diabetes mellitus (34\%), followed by hypertension (31.8\%), obstructive sleep apnea (20.8\%), and chronic kidney disease (10.5\%).

\section{Clinical Characteristics Data}

(Table 2) Cough was the most frequent symptom, reported in $78.2 \%$ of patients. Other symptoms frequently reported were fever (62.1\%), rhinorrhea or nasal congestion (35.1\%), dyspnea (31.2\%), myalgias (29.1\%), fatigue (22.8\%) and chills $(22.2 \%)$. The median duration of cough to ED presentation was 3 days (IQR 2-7). Headache was the most common neurological symptom reported in $12.2 \%$ of patients. Diarrhea was found in $8.9 \%$ of patients. Presenting vital signs showed a median heart rate of 92 bpm (IQR 80-104) and median temperature 99.1 ${ }^{\circ} \mathrm{F}$ (IQR 98.6-100.0).

\section{Home Medications}

(Table 3) Nonsteroidal anti-inflammatory drugs (NSAIDs) use was reported in $35.8 \%$ of patients and angiotensinconverting enzyme inhibitors (ACEI) or angiotensin II receptor blockers (ARBs) in 28.7\%. About a third of patients (33.1\%) were taking a vitamin D supplement, and $5.5 \%$ were on anticoagulation.

\section{Outcome Data}

The outcome data were collected through April 12, 2020. Out of 821 COVID-19 patients who were discharged home at the time of the coronavirus test, 158 patients $(19.2 \%)$ returned for at least one subsequent visit to ED. Twentyone patients $(13.3 \%)$ returned twice to the ED for reevaluation, and one patient returned 4 times to the ED but was never admitted to the hospital. The median time to the initial follow-up ED visit was 5 days (IQR 3-7). From the patients that had a follow-up ED visit, 86/158 (54.4\%) resulted in admissions to the hospital, with an overall admission rate for the entire cohort of $10.5 \%$. Of the patients admitted, $11(12.8 \%)$ died with an overall mortality of $1.3 \%$, and the median time to death was 7 days (IQR 3-13) from the admission date. (Table 4) At the time of outcome collection, 10 patients were still admitted to the hospital, including 6 patients in the intensive care unit (ICU). Assuming the worst-case scenario, if none of the ICU patients survive, the inpatient mortality of this cohort could be as high as $2.1 \%$. The mortality rate would be $2.6 \%$ if none of the patients currently in the hospital survive. From our cohort, most COVID-19 patients (80.8\%) never returned to the ED for follow-up.

The patients eventually admitted to the hospital were older (mean age 54.4 vs 48.7 years, $p=0.002$ ), had higher BMI (35.4 vs $\left.31.9 \mathrm{~kg} / \mathrm{m}^{2}, p=0.004\right)$, were more likely male 
Table I Demographic Characteristics and Comorbidities of Patients with COVID-19; Comparison in Between Outpatient Patients That Remained Home in Self-Isolation vs Admitted Patients to the Hospital

\begin{tabular}{|c|c|c|c|c|}
\hline Study Population & $\begin{array}{l}\text { All Patients } \\
\begin{array}{l}\text { No. (\%); } \\
\text { N = 82I }\end{array}\end{array}$ & $\begin{array}{l}\text { Outpatient Patients } \\
\begin{aligned} \text { No. (\%); } \\
\text { N }=735\end{aligned}\end{array}$ & $\begin{array}{c}\text { Admitted Patients } \\
\begin{array}{c}\text { No. (\%); } \\
\text { N = 86 }\end{array}\end{array}$ & p-value \\
\hline Age, mean $\pm S D, y$ & $49.3 \pm 15.7$ & $48.7 \pm 15.7$ & $54.4 \pm 15.6$ & 0.002 \\
\hline Male Sex, No (\%) & $384(46.8 \%)$ & 334 (45.4\%) & 50 (58.1\%) & 0.026 \\
\hline $\begin{array}{l}\text { Ethnicity } \\
\text { Caucasian } \\
\text { African American } \\
\text { Other } \\
\text { Body Mass index, mean } \pm \mathrm{SD}, \mathrm{kg} / \mathrm{m}^{2}\end{array}$ & $\begin{array}{c}303(36.9 \%) \\
452(55.1 \%) \\
66(8.0 \%) \\
32.4 \pm 7.7\end{array}$ & $\begin{array}{c}269(36.6 \%) \\
405(55.1 \%) \\
61(8.3 \%) \\
31.9 \pm 7.7\end{array}$ & $\begin{array}{c}34(39.5 \%) \\
47(54.6 \%) \\
5(5.8 \%) \\
35.4 \pm 7.2\end{array}$ & $\begin{array}{l}0.679 \\
0.004\end{array}$ \\
\hline $\begin{array}{l}\text { Pulmonary comorbidities } \\
\text { COPD } \\
\text { Bronchial Asthma } \\
\text { OSA } \\
\text { Interstitial Lung Disease } \\
\text { Pulmonary hypertension } \\
\text { Sarcoidosis } \\
\text { VTE }\end{array}$ & $\begin{array}{c}74(9.0 \%) \\
92(11.2 \%) \\
17 \mid(20.8 \%) \\
0(0 \%) \\
8(1.0 \%) \\
6(0.7 \%) \\
103(12.5 \%)\end{array}$ & $\begin{array}{c}40(5.4 \%) \\
80(10.9 \%) \\
140(19.0 \%) \\
0(0.0 \%) \\
8(1.1 \%) \\
4(0.5 \%) \\
92(12.5 \%)\end{array}$ & $\begin{array}{c}34(39.5 \%) \\
12(14.0 \%) \\
31(36.0 \%) \\
0(0.0 \%) \\
0(0.0 \%) \\
2(2.3 \%) \\
\text { I }(12.8 \%)\end{array}$ & $\begin{array}{c}<0.001 \\
0.393 \\
<0.001 \\
\text { NA } \\
1.000 \\
0.123 \\
0.942\end{array}$ \\
\hline $\begin{array}{l}\text { Metabolic comorbidities } \\
\text { Diabetes Mellitus } \\
\text { Prediabetes } \\
\text { HTN } \\
\text { HLD }\end{array}$ & $\begin{array}{l}279(34.0 \%) \\
82(10.2 \%) \\
261(31.8 \%) \\
168(20.5 \%)\end{array}$ & $\begin{array}{l}215(29.3 \%) \\
62(8.4 \%) \\
216(29.4 \%) \\
139(18.9 \%)\end{array}$ & $\begin{array}{l}64(74.4 \%) \\
22(25.6 \%) \\
45(52.3 \%) \\
29(33.7 \%)\end{array}$ & $\begin{array}{l}<0.001 \\
<0.001 \\
<0.001 \\
0.001\end{array}$ \\
\hline $\begin{array}{l}\text { Cardiac and renal comorbidities } \\
\text { Cardiac arrhythmia } \\
\text { Coronary Artery Disease } \\
\text { Heart Failure } \\
\text { CKD }\end{array}$ & $\begin{array}{l}116(14.1 \%) \\
125(15.2 \%) \\
18(2.2 \%) \\
86(10.5 \%)\end{array}$ & $\begin{array}{l}101(13.7 \%) \\
101(13.7 \%) \\
16(2.2 \%) \\
71(9.7 \%)\end{array}$ & $\begin{array}{c}15(17.4 \%) \\
24(27.9 \%) \\
2(2.3 \%) \\
15(17.4 \%)\end{array}$ & $\begin{array}{l}0.351 \\
0.001 \\
1.000 \\
0.026\end{array}$ \\
\hline $\begin{array}{l}\text { Neurological comorbidities } \\
\text { Cognitive impairment or dementia } \\
\text { Seizure disorder } \\
\text { Transient Ischemic Attack } \\
\text { Cerebrovascular Disease }\end{array}$ & $\begin{array}{l}153(18.6 \%) \\
150(18.3 \%) \\
48(5.8 \%) \\
7 \mid(8.6 \%)\end{array}$ & $\begin{array}{l}123(16.7 \%) \\
123(16.7 \%) \\
40(5.4 \%) \\
61(8.3 \%)\end{array}$ & $\begin{aligned} 30 & (34.9 \%) \\
27 & (31.4 \%) \\
8 & (9.3 \%) \\
10 & (11.6 \%)\end{aligned}$ & $\begin{array}{l}<0.001 \\
0.001 \\
0.149 \\
0.299\end{array}$ \\
\hline $\begin{array}{l}\text { Other } \\
\text { Chronic Liver Disease } \\
\text { Chronic Hepatitis B } \\
\text { Chronic Hepatitis C } \\
\text { Rheumatologic disorders } \\
\text { Inflammatory bowel disease } \\
\text { Psychiatric Disorder } \\
\text { Cancer } \\
\text { Immunosuppression } \\
\text { None of the above }\end{array}$ & $\begin{array}{c}\text { II (I.3\%) } \\
\text { I (0.1\%) } \\
\text { I (0.1\%) } \\
\text { I } 46(17.8 \%) \\
7(0.9 \%) \\
103(12.5 \%) \\
75(9.1 \%) \\
\text { II (1.3\%) } \\
295(35.9 \%)\end{array}$ & $\begin{array}{c}\text { II }(1.5 \%) \\
I(0.1 \%) \\
I(0.1 \%) \\
122(16.6 \%) \\
7(1.0 \%) \\
94(12.8 \%) \\
61(8.3 \%) \\
10(1.4 \%) \\
292(39.7 \%)\end{array}$ & $\begin{aligned} & 0(0.0 \%) \\
0 & (0.0 \%) \\
0 & (0.0 \%) \\
24 & (28.9 \%) \\
0 & (0.0 \%) \\
9 & (10.5 \%) \\
14 & (16.3 \%) \\
1 & (1.2 \%) \\
3 & (3.5 \%)\end{aligned}$ & $\begin{array}{l}0.617 \\
1.000 \\
1.000 \\
0.010 \\
1.000 \\
0.538 \\
0.015 \\
1.000 \\
<0.001\end{array}$ \\
\hline
\end{tabular}

Note: $p$ value applies for comparison in between outpatient patients and admitted patients.

Abbreviations: SD, standard deviation; No., number; y, year; CKD, chronic kidney disease; COPD, chronic obstructive pulmonary disease; OSA, Obstructive Sleep Apnea; HTN, hypertension; HLD, hyperlipidemia; VTE, venous thromboembolic disease; NA, not applicable. 
Table 2 Clinical Presentation

\begin{tabular}{|c|c|c|c|}
\hline $\begin{array}{l}\text { Initial Presenting Symptoms } \\
\mathbf{N}=\mathbf{8 2} \text { I }\end{array}$ & No. (\%) & $\begin{array}{l}\text { Initial Presenting Symptoms } \\
\text { (Continued) }\end{array}$ & No. (\%) \\
\hline Constitutional symptoms & & Lower Respiratory symptoms & \\
\hline Fever & $510(62.1 \%)$ & Cough & 645 (78.2\%) \\
\hline Chills & $182(22.2 \%)$ & Duration of cough, median (IQR), d & $3.0(2-7)$ \\
\hline Fatigue & $187(22.8 \%)$ & Sputum Production & $26(3.2 \%)$ \\
\hline Anorexia & 37 (4.5\%) & Hemoptysis & $33(4.0 \%)$ \\
\hline Malaise & $4 \mathrm{I}(5.0 \%)$ & Dyspnea & 256 (3I.2\%) \\
\hline Diaphoresis & $24(2.9 \%)$ & Chest pain & 81 (9.9\%) \\
\hline Musculoskeletal symptoms & & Paroxysmal nocturnal dyspnea & $\mathrm{I}(0.1 \%)$ \\
\hline Myalgias & $239(29.1 \%)$ & Neurological symptoms & \\
\hline Arthralgia & II (1.3\%) & Headache & $100(12.2 \%)$ \\
\hline Lower extremity swelling & $4(0.5 \%)$ & Confusion & $8(1.0 \%)$ \\
\hline Gastrointestinal & & Dizziness & 14 (1.7\%) \\
\hline Abdominal pain & $28(3.4 \%)$ & Lightheadedness & 47 (5.7\%) \\
\hline Nausea & 71 (8.6\%) & Syncope & $18(2.2 \%)$ \\
\hline Vomiting & $34(4.1 \%)$ & & \\
\hline Diarrhea & 73 (8.9\%) & Presenting Vital Signs & \\
\hline Miscellaneous symptoms & & Blood pressure & \\
\hline Dysguesia, hypogeusia or aguesia & II (I.3\%) & Systolic $(n=703)$ & $131.0(\mid 18-144)$ \\
\hline Hyposmia, dysosmia or anosmia & 85 (10.4\%) & Diastolic $(n=703)$ & $74.0(65-84)$ \\
\hline Rash & $2(0.2 \%)$ & Heart rate, bpm $(n=730)$ & $92.0(80-104)$ \\
\hline Upper respiratory tract symptoms & & Respiratory rate, breaths/min $(n=698)$ & $18.0(18-20)$ \\
\hline Sore throat & $103(12.5 \%)$ & Temperature, ${ }^{\circ} \mathrm{C}(\mathrm{n}=727)$ & $99.1(98.6-100.0)$ \\
\hline Rhinorrhea or nasal congestion & $288(35.1 \%)$ & Oxygen saturation, \% $(n=729)$ & $97.0(96-99)$ \\
\hline
\end{tabular}

Abbreviations: bpm, beats per minute; No., number; d, days; IQR, interquartile range.

( $58.1 \%$ vs $45.4 \%, p=0.026$ ), and were more likely to have hypertension ( $52.3 \%$ vs $29.4 \%, p<0.001)$, diabetes mellitus $(74.4 \%$ vs $29.3 \%, p<0.001)$ or prediabetes $(25.6 \%$ vs

Table 3 Home Prescription Medications

\begin{tabular}{|l|c|}
\hline Study Population $\mathbf{N}=\mathbf{8 2} \mathbf{I}$ & No. (\%) \\
\hline Medication & $294(35.8 \%)$ \\
NSAIDs & $45(5.5 \%)$ \\
Anticoagulants & $162(19.7 \%)$ \\
Antiplatelet agents & \\
\hline Antihypertensives & $138(16.8 \%)$ \\
ACE-I & $98(11.9 \%)$ \\
ARBs & $163(19.9 \%)$ \\
Glucocorticoids & $187(22.8 \%)$ \\
Lipid lowering therapy & $33(4.0 \%)$ \\
Antiviral therapy & $272(33.1 \%)$ \\
Vitamin D supplements & \\
\hline
\end{tabular}

Notes: Anticoagulants include warfarin and direct oral anticoagulants; antiplatelet agents include aspirin, clopidogrel, prasugrel, and ticagrelor; Lipid lowering therapy: include statin therapy and ezetimibe; antiviral therapy include acyclovir/valacyclovir only.

Abbreviations: SD, standard deviation; No., number; $y$, year; NSAIDs, nonsteroidal anti-inflammatory medication; ACE-I, angiotensin converting enzymeinhibitor; ARB, angiotensin receptor blocker.
$8.4 \%, p<0.001)$, COPD (39.5\% vs $5.4 \%, p<0.001)$, and OSA ( $36 \%$ vs $19 \%, p<0.001)$, dementia ( $34.9 \%$ vs $16.7 \%$, $p<0.001)$, chronic kidney disease (CKD) $(17.4 \%$ vs $9.7 \%$, $p=0.026)$ or cancer $(16.3 \%$ vs $8.3 \%, p=0.015)$. On multivariate analysis, only higher BMI (aOR:1.05 (1.01-1.09), $p=0.015$ ), diabetes mellitus (aOR:3.27 (1.49-7.15), $p=0.003$ ), and OSA (aOR:3.44 (1.11-10.65), $p=0.032$ )

Table 4 Outcomes

\begin{tabular}{|l|c|}
\hline Outcomes (No.=82 I) & No. (\%) \\
\hline Follow-up ED visit & I58 (I9.2\%) \\
\hline Time to ED visit, median(IQR), d (No=I82) & $5.0(3-7)$ \\
\hline Length of Stay (LOS), median(IQR), d (No=76) & $4.0(3-7)$ \\
\hline Admitted inpatient after follow-up ED visit & $86(54.4 \%)$ \\
\hline Mortality & II (I.3\%) \\
\hline Time to death from admission, median(IQR), d & $7(3-13)$ \\
\hline
\end{tabular}

Abbreviations: No., number; ED, emergency department; IQR, interquartile range; d, days. 
were independent correlates of hospital admission. Older age $(p=0.345)$, HTN $(p=0.999)$, COPD $(p=0.721)$, dementia $(p=0.852)$, and CKD $(p=0.520)$ were not statistically significant correlates of hospital admission on multivariate analysis.

\section{Discussion}

In this large cohort of patients with COVID-19 and underlying comorbid conditions who were sent home to self-isolate, the majority were younger females of African American descent with an average body mass index within the obesity class I range and never smokers. The patients eventually admitted to the hospital were older, had higher BMI (obesity class II) and were more likely male. The literature on the demographics of patients with COVID-19 at high risk for severe disease who are sent home to self-isolate is limited.

From March 1, 2020 to July 29, 2020, more than 80,000 cases of COVID-19 were reported in Michigan with a significantly higher incidence rate among African Americans, women, and individuals with lower income. ${ }^{20}$ According to the Michigan Department of Health and Human Services, overall cases aged 30-59 constitute 59\% of the affected population with COVID-19, of which $33 \%$ were African-Americans. ${ }^{21}$ Of note, African-Americans comprised $40 \%$ of COVID-19 deaths in Michigan. ${ }^{21}$ The higher percentage of COVID-19 cases among African Americans in our study $(55.1 \%)$ could be attributed to the aforementioned racial disparities or attributed to Beaumont Health's broad network of services provided to highly populous counties with large African-American communities. Much can be discussed about the factors contributing to the disproportionate rates of COVID-19 cases among African Americans, but existing literature suggests health conditions such as type 2 diabetes and hypertension as well as social determinants such as working as essential employees, lower socioeconomic status, increased exposure to family or someone outside the household diagnosed with COVID-19, and limited access to health care as important risk factors. ${ }^{20,22,23}$ Our findings highlight the importance of continued public health efforts to understand and address risk factors to outcome disparities among different racial and ethnic groups.

Our study also found that the most common symptoms reported upon ED presentation were fever, dyspnea, rhinorrhea, cough, myalgia, fatigue and chills. These results are consistent with WHO findings of fever, fatigue, and dry cough as the most common COVID-19 symptoms, along with previously reported less common symptoms including myalgias, nasal congestion, rhinorrhea, sore throat, and diarrhea. ${ }^{20}$ Among 138 hospitalized patients with COVID-19 pneumonia in Wuhan, the most common clinical features at the onset of illness were also fever $(99 \%)$, fatigue $(70 \%)$, dry cough $(59 \%)$, anorexia $(40 \%)$, myalgias $(35 \%)$, dyspnea (31\%), and sputum production (27\%). ${ }^{15}$ Although these appear to be the most common presenting symptoms, less often patients may even present with sensorimotor disabilities. ${ }^{24}$ It appears that the inpatient and outpatient commonly reported symptoms are similar.

Diabetes mellitus was the most common comorbidity in our cohort, followed by hypertension, hyperlipidemia and obstructive sleep apnea. Although a requirement for testing included comorbid conditions, more than a third of the patients from our cohort did not have evidence of these medical problems in our database. This finding could have been because the cohort was truly healthier than the previously reported inpatient cohort and did not fully meet MDHHS criteria and/or their medical records were incomplete with missing data about risk factors for severe disease. Comparing the patients who were eventually admitted to the hospital with the patients who never required an admission, hypertension, diabetes mellitus, prediabetes, OSA, COPD, hyperlipidemia, cognitive impairment or dementia, CKD and cancer were associated with more severe disease requiring hospital admission. Worse outcomes have been reported before in patients with COPD, diabetes mellitus, hypertension, and malignancy. ${ }^{23}$ A retrospective study in Italy also showed that increased age, impaired renal function and elevated C-reactive Protein were also associated with poorer outcomes. ${ }^{25}$ This is consistent with the inpatient findings in Beaumont Health, Michigan, that reported that older age and comorbidity are independent mortality predictors. ${ }^{26}$ Furthermore, a cumulative increased risk of severe disease has been reported with an increase in the number of medical comorbidities. There are other comorbidities that are more unique to our patient population, and their impact on disease progression is less understood. The CDC states that patients suffering from severe obesity (BMI $\geq 40 \mathrm{~kg} /$ $\mathrm{m}^{2}$ ) and chronic kidney disease (CKD) of any stage are at increased risk for severe illness. In 2018, an estimated $32.5 \%$ of Michigan adults were classified as obese (BMI $\left.\geq 30 \mathrm{~kg} / \mathrm{m}^{2}\right) .{ }^{27}$ Likewise, more than one million Michigan adults (or 1 in 7) suffer from chronic kidney disease. ${ }^{28}$ Future studies should investigate associations between disease progression and comorbidities like obesity and CKD, which are more specific to the American population. 
Many patients were taking NSAIDs, ACEIs or ARBs. The effects of NSAIDs on clinical outcomes in COVID-19 infections remain unclear, and the World Health Organization (WHO) have retracted their prior recommendation to avoid NSAID use. The Food and Drugs Administration (FDA) reports the absence "of current scientific evidence connecting use of NSAIDs to worsening COVID-19 symptoms". ${ }^{29,30}$ The American College of Cardiology/American Heart Association (ACC/AHA) guidelines currently state that there are no experimental or clinical data demonstrating beneficial or adverse outcomes with background use of ACEI, ARBs or other renin-angiotensin aldosterone system (RAAS) antagonists in COVID-19 or among COVID-19 patients with a history of cardiovascular disease treated with such agents. Continuation of RAAS antagonists for those patients who are currently prescribed such agents for indications for which these agents are known to be beneficial, such as heart failure, hypertension, or ischemic heart disease is recommended. ${ }^{31}$ Another multicenter observational study and meta-analysis in Italy showed that the use of ACEI and ARBs was not associated with increased severity or in hospital mortality in patients with COVID-19. ${ }^{32}$ According to another retrospective multicenter study published by the American Heart Association, the in-hospital use of ACE-inhibitors/ARBs was associated with a lower risk of all-cause mortality. ${ }^{33}$ A jointly published statement by the American Heart Association and Heart Failure Society of America, recommends continuing ACE-inhibitors/ARB in patients with co-existing hypertension and COVID-19. ${ }^{31}$

The current worldwide COVID-19 mortality is $6.9 \%$, with large variations within different countries with US mortality being $3.8 \%$, Spain $10.2 \%$, Italy $12.8 \%$ and China $4.0 \% .{ }^{34,35}$ Our cohort had a low mortality rate likely because a third of the patients had a mild clinical presentation and no overt comorbidities. Among 44,672 confirmed cases of COVID-19 in China, the fatality rate for patients without reported comorbidities was $0.9 \%$, while the fatality rate for patients with cardiovascular disease, diabetes mellitus, and chronic respiratory disease were $10.5 \%, 7.3 \%$, and $6.3 \%$, respectively. ${ }^{36}$

\section{Limitations and Strengths}

This study is limited by the retrospective nature of its design. Most of the data were limited to the electronic medical record documentation and adjudication of outcomes via individual chart review was not performed. Outcomes were reported only if the events occurred in our health system. Strengths of this study include a large sample size and thorough manual data collection confirming the disposition of the patients at the time of the COVID-19 assessment and their clinical symptoms upon presentation to ED. Follow-up time was sufficient to capture $92.4 \%$ of the outcomes.

\section{Conclusion}

This is the first large retrospective multicenter cohort to report on clinical characteristics and outcomes of COVID-19 patients that were discharged home to selfisolate after initial ED visit. Only $19.2 \%$ of patients returned to ED for re-evaluation from which $54.4 \%$ got admitted. Higher BMI, diabetes mellitus and OSA have been independently correlated with hospital admission. Overall mortality rate was $1.3 \%$. The information provided in this study could serve to guide anticipation of worse clinical outcomes in certain individuals when comparing age, gender, race and co-morbid conditions. Classifying patients that may be at an increased risk of poor outcomes would allow for closer monitoring, earlier intervention and possible reduction in mortality. A better understanding of disease progression among COVID-19 patients as they self-isolate will prove useful in minimizing the burden of disease.

\section{Data Sharing Statement}

The datasets used and/or analyzed during the current study are available from the corresponding author on reasonable request.

\section{Ethics Approval and Consent to Participate}

The Beaumont Health Institutional Review Board under the exempt category approved the current study. As our study was of a retrospective nature, patient consent to review their medical records was waived by the IRB because of the inability of obtaining consent in this scenario. The research involved no greater than minimal risk and no procedures for which written consent is normally required were performed. Patient data was kept confidentiality and compliant with the Declaration of Helsinki.

\section{Acknowledgments}

The authors would like to thank Julie George, MS for the biostatistical support and Madhavi Purekar for data management. 


\section{Author Contributions}

All authors made a significant contribution to the work reported, whether that is in the conception, study design, execution, acquisition of data, analysis and interpretation, or in all these areas; took part in drafting, revising or critically reviewing the article; gave final approval of the version to be published; have agreed on the journal to which the article has been submitted; and agree to be accountable for all aspects of the work data analysis.

\section{Funding}

This study had no funding source.

\section{Disclosure}

The authors declare that they have no competing interests.

\section{References}

1. Zhu N, Zhang D, Wang W, et al. A novel coronavirus from patients with pneumonia in China, 2019. N Engl J Med. 2020;382 (8):727-733. PMID: 31978945. doi:10.1056/NEJMoa2001017

2. Lu R, Zhao X, Li J, et al. Genomic characterization and epidemiology of 2019 novel coronavirus: implications for virus origins and receptor binding. Lancet. 2020;395(10224):565-574. PMID: 32007145. doi:10.1016/S0140-6736(20)30251-8

3. Lai CC, Shih TP, Ko WC, Tang HJ, Hsueh PR. Severe acute respiratory syndrome coronavirus 2 (SARS-CoV-2) and coronavirus disease-2019 (COVID-19): the epidemic and the challenges. Int J Antimicrob Agents. 2020;55(3):105924. doi:10.1016/j.ijantimicag.2020.105924

4. Zhou P, Yang XL, Wang XG, et al. A pneumonia outbreak associated with a new coronavirus of probable bat origin. Nature. 2020;579 (7798):270-273. PMID: 32015507. doi:10.1038/s41586-020-2012-7

5. Ji W, Wang W, Zhao X, Zai J, Li X. Cross-species transmission of the newly identified coronavirus 2019-nCoV. J Med Virol. 2020. doi:10.1002/jmv.25682

6. Rothan HA, Byrareddy SN. The epidemiology and pathogenesis of coronavirus disease (COVID-19) outbreak. J Autoimmun. 2020;109:102433. doi:10.1016/j.jaut.2020.102433

7. Del Rio C, Malani PN. COVID-19 - new insights on a rapidly changing epidemic. JAMA. 2020;323(14):1339. doi:10.1001/jama.2020.3072

8. Hindson J. COVID-19: faecal-oral transmission? Nat Rev Gastroenterol Hepatol. 2020;17(5):259. doi:10.1038/s41575-020-0295-7

9. Centers for Disease Control and Prevention. Trends in Number of COVID-19 Cases and Deaths in the US Reported to CDC, by State/ Territory. Available from: https://covid.cdc.gov/covid-data-tracker /\#trends_totalandratecasestotalrate. Accessed March 31, 2021.

10. Michigan data: coronavirus. Department of Michigan Health and Human Services; February, 2021. Available from: https://www.michi gan.gov/coronavirus/0,9753,7-406-98163_98173-,00.html. Accessed March 31, 2021.

11. Guan WJ, Ni ZY, Hu Y, et al. Clinical characteristics of coronavirus disease 2019 in China. $N$ Engl J Med. 2020;382(18):1708-1720. PMID: 32109013. doi:10.1056/NEJMoa2002032

12. Popov GT, Baymakova M, Vaseva V, Kundurzhiev T, Mutafchiyski V. Clinical characteristics of hospitalized patients with COVID-19 in Sofia, Bulgaria. Vector Borne Zoonotic Dis. 2020;20 (12):910-915. PMID: 33054699. doi:10.1089/vbz.2020.2679
13. Lechien JR, Chiesa-Estomba CM, Place S, et al. Clinical and epidemiological characteristics of 1420 European patients with mild-tomoderate coronavirus disease 2019. J Intern Med. 2020;288 (3):335-344. PMID: 32352202. doi:10.1111/joim.13089

14. Wu Z, McGoogan JM. Characteristics of and important lessons from the coronavirus disease 2019 (COVID-19) outbreak in China. JAMA. 2020;323(13):1239. doi:10.1001/jama.2020.2648

15. Management of Patients with Confirmed 2019-nCoV. Centers for Disease Control and Prevention; February, 2021. Available from: https://covid.cdc.gov/covid-data-tracker/\#hospitalizations. Accessed March 31, 2021.

16. Cheng A, Caruso D, McDougall C. Outpatient management of COVID-19: rapid evidence review. Am Fam Physician. 2020;102 (8):478-486. PMID: 33064422.

17. McCullough PA, Kelly RJ, Ruocco G, et al. Pathophysiological basis and rationale for early outpatient treatment of SARS-CoV-2 (COVID-19) infection. Am J Med. 2021;134(1):16-22. PMID: 32771461. doi:10.1016/j.amjmed.2020.07.003

18. Laboratory testing strategy recommendations for COVID-19. World Health Organization; Available from: https://apps.who.int/iris/bit stream/handle/10665/331509/WHO-COVID-19-lab_testing-2020. 1-eng.pdf. Accessed March 31, 2021.

19. Frequently asked questions about coronavirus disease 2019. Department of Michigan Health and Human Services. Available from: https://www. michigan.gov/documents/mdhhs/2019-nCoV_Web_FAQ_Final_02.07. 20_680693_7.pdf. Accessed March 31, 2021.

20. World Health Organisation. Clinical management of severe acute respiratory infection when novel coronavirus $(\mathrm{nCoV})$ infection is suspected. Available from: https://apps.who.int/iris/handle/10665/ 330854. Accessed March 31, 2021.

21. Michigan data. Department of Michigan Health and Human Services. Available from: https://www.michigan.gov/coronavirus/ 0,9753,7-406-98163_98173-,00.html. Accessed March 31, 2021.

22. Wang D, Hu B, Hu C, et al. Clinical characteristics of 138 hospitalized patients with 2019 novel coronavirus-infected pneumonia in Wuhan, China. JAMA. 2020;323(11):1061. doi:10.1001/jama.2020.1585

23. Guan W, Liang W, Zhao Y, et al. Comorbidity and its impact on 1590 patients with Covid-19 in China: a nationwide analysis. Eur Respir J. 2020;55(5):2000547. doi:10.1183/13993003.00547-2020

24. Di Gennaro F, Marotta C, Storto M, et al. SARS-CoV-2 transmission and outcome in neuro-rehabilitation patients hospitalized at neuroscience hospital in Italy. Mediterr J Hematol Infect Dis. 2020;12 (1):e2020063. doi:10.4084/MJHID.2020.063

25. Di Castelnuovo A, Bonaccio M, Costanzo S, et al.; Covid-19 risk and treatments (CORIST) collaboration (2020). Common cardiovascular risk factors and in-hospital mortality in 3894 patients with COVID-19: survival analysis and machine learning-based findings from the multicentre Italian CORIST Study. Nutr Metab Cardiovasc Dis. 2020;30(11):1899-1913. doi:10.1016/j.numecd.2020.07.031

26. Imam Z, Odish F, Gill I, et al. Halalau, older age and comorbidity are independent mortality predictors in a large cohort of 1305 COVID-19 patients in Michigan, United States. J Intern Med. 2020;288 (4):469-476. doi:10.1111/joim.13119

27. Obesity in Michigan 2018 update prepared by the Michigan Department of Health and Human Services (MDHHS) cardiovascular health, nutrition and physical activity section key facts obesity among michigan adults (2007-2016) data source: Michigan Behavioral Risk Factor Surveillance System (MiBRFSS) 2007-2016. Available from: http://www.michigan.gov/preventobesity. Accessed April 15, 2020.

28. For immediate release chronic kidney disease now affects one million Michigan adults. Available from: https://www.nkfm.org/sites/default/ files/documents/pages/r_-_kidney_month_2020_-_web.pdf. Accessed March 31, 2021. 
29. Russell CD, Millar JE, Baillie JK. Clinical evidence does not support corticosteroid treatment for 2019-nCoV lung injury. Lancet. 2020;395(10223):473-475. doi:10.1016/S0140-6736(20)30317-2

30. FDA advises patients on use of non-steroidal anti-inflammatory drugs (NSAIDs) for COVID-19. FDA. Available from: https://www.fda. gov/drugs/drug-safety-and-availability/fda-advises-patients-use-nonsteroidal-anti-inflammatory-drugs-nsaids-covid-19. Accessed March 31, 2021.

31. American College of Cardiology. HFSA/ACC/AHA Statement Addresses Concerns Re: Using RAAS Antagonists in COVID-19. ACC News Story; 2020.

32. Di Castelnuovo A, Costanzo S, Antinori A; COVID-19 RISk and Treatments (CORIST) Collaboration. RAAS inhibitors are not associated with mortality in COVID-19 patients: findings from an observational multicenter study in Italy and a meta-analysis of 19 studies. Vascul Pharmacol. 2020;135:106805. doi:10.1016/j.vph.2020.106805

33. Zhang P, Zhu L, Cai J, et al. Association of inpatient use of angiotensin converting enzyme inhibitors and angiotensin II receptor blockers with mortality among patients with hypertension hospitalized with COVID-19. Circ Res. 2020.
34. Grasselli G, Zangrillo A, Zanella A, et al. Baseline characteristics and outcomes of 1591 patients infected with SARS-CoV-2 admitted to ICUs of the Lombardy Region, Italy. JAMA. 2020;323(16):1574. doi:10.1001/jama.2020.5394

35. Novel Coronavirus Pneumonia Emergency Response Epidemiology T. [The epidemiological characteristics of an outbreak of 2019 novel coronavirus diseases (COVID-19) in China]. Zhonghua Liu Xing Bing Xue Za Zhi. 2020;41(2):145-151. Chinese. doi:10.3760/cma.j.issn.0254-6450.202 0.02 .003

36. Zhou F, Yu T, Du R, et al. Clinical course and risk factors for mortality of adult inpatients with COVID-19 in Wuhan, China: a Retrospective Cohort Study. Lancet. 2020;395(10229):1054-1062. doi:10.1016/S0140-6736(20)30566-3

\section{Publish your work in this journal}

The International Journal of General Medicine is an international, peer-reviewed open-access journal that focuses on general and internal medicine, pathogenesis, epidemiology, diagnosis, monitoring and treatment protocols. The journal is characterized by the rapid reporting of reviews, original research and clinical studies across all disease areas. The manuscript management system is completely online and includes a very quick and fair peer-review system, which is all easy to use. Visit http://www.dovepress.com/ testimonials.php to read real quotes from published authors. 